\title{
Aspectual coercion and the typology of change of state predicates ${ }^{1}$
}

\author{
ANDREW KOONTZ-GARBODEN
}

\author{
Stanford University \\ (Received I9 January 2006; revised I2 September 2006)
}

The point of departure of this paper is the consideration of how words with the meanings of property concept states (states that are lexicalized as adjectives in languages that have that lexical category, cf. Dixon I982), e.g. 'red', are related to words denoting their corresponding change of state, e.g. 'redden'. It is shown that while many languages relate words with these meanings to one another via some morpholexical process, this is not so in the Polynesian language Tongan. A detailed case study shows that in this language there are no non-causative change of state lexemes based on property concepts. Rather, these meanings are derived pragmatically from verbs denoting the corresponding state via aspectual coercion (Moens \& Steedman I988, Jackendoff I997, de Swart I998, Zucchi I998, Michaelis 2004). This finding is shown to have consequences for the understanding of the typology of change of state predicates (Koontz-Garboden 2005, 2006, Koontz-Garboden \& Levin 2005) and for theories of event structure: (a) the typological space is broader than previously thought and (b) theories of event structure need to be reconsidered in order to account for the postlexical derivation of meaning.

\section{INTRODUCTION: STATES AND THEIR CORRESPONDING CHANGES OF STATE}

Investigation of the temporal properties of verbs, i.e. what has been called their aktionsart, is among the oldest areas of linguistic inquiry (see Binnick

[I] I am grateful to the following people for comments and data related to this work: Doug Ball, John Beavers, Elena Benedicto, Lev Blumenfeld, Melissa Bowerman, Joan Bresnan, Luis Casillas Martinez, Eve Clark, Mike Dukes, Hana Filip, Ivan García-Ảlvarez, Martin Haspelmath, Shelly Lieber, Jimmy Lin, Yuko Otsuka, Sergei Tatevosov, and Judith Tonhauser. Paul Kiparsky and Beth Levin have seen this work through all of its stages and have provided crucial feedback at each of them, for which I am grateful. Martina Faller, Itamar Francez, and Ashwini Deo provided particularly helpful feedback at critical stages, as did two anonymous $J L$ reviewers. Data from Tongan, unless another source is given, are drawn from fieldwork carried out in 2003-2004 in East Palo Alto, CA, with Sisilia Lutui, a marvelous consultant, for whose patience and wisdom I am especially grateful. People interested in the data for phonological reasons should be warned that I have not marked vowel length or the definitive accent consistently in the examples. This research was supported in part by NSF Grant BCS-0004437 (Beth Levin, P.I.) and by Graduate Research Funds from the Department of Linguistics at Stanford University. 
I99I for overview). Study of verbal aspect from a typological perspective, particularly with respect to the derivational relationship between words with different, but related, aspectual categories, is a relatively newer endeavor, however. Talmy (1985), Croft (I990), and Levin (200I) observe that all languages seem to have words, often with a common root, that for a given state describe the aspectual notions in (I).

(I) (a) being in a state

(b) coming to be in a state

(c) causing to come to be in a state (state)

(non-causative change of state)

(causative change of state)

For example, in English, for the state of 'looseness' there are stative loose, the non-causative change of state (COS) loosen, and the causative COS loosen, as shown in (2).

(2) (a) The knot is loose.

(state)

(b) The knot loosened. (non-causative COS)

(c) Alex loosened the knot. (causative COS)

How words with these sorts of meanings are derivationally related to one another both morphologically and semantically is a question of longstanding interest for many otherwise very different varieties of linguistic theory. In the formal literature, the question has been of interest going back at least to Lakoff (1970), and continues to be of relevance to many theories of lexical semantics (Dowty 1979, Foley \& Van Valin 1984, Levin \& Rappaport Hovav I995, Hale \& Keyser 2002) and syntax (Baker 2003, Alexiadou \& Anagnostopoulou 2004, Embick 2004, Lin 2004). In the functional-typological tradition, researchers since Nedjalkov \& Silnitsky (1973), and more recently Croft (I990) and Haspelmath (I993), have been interested in how the different languages of the world formally relate words with the meanings in $(\mathrm{Ib}, \mathrm{c})$, the so-called causative/inchoative alternation. Given the fact that there exists both a semantic and frequently a morphological relationship between the word encoding the notion in (ra) and those in $(\mathrm{Ib}, \mathrm{c})$, an obvious extension of these lines of research is to examine how words denoting the latter kinds of meaning are related to words denoting the former. Koontz-Garboden \& Levin (2005) and Koontz-Garboden (2005, 2006) are initial investigations in this area. Among other things, they build on Dixon's (1982) observation that words denoting property concepts (states that are lexicalized as adjectives in languages that have that lexical category, cf. Dixon 1982) belong to different lexical categories in different languages, showing that the lexical category of words denoting property concepts has an impact on how words with these meanings are related to words denoting the corresponding change of state. For example, consider the data in (3)-(4). 
(3) O’odham (Hale \& Keyser I998: 92)

ADJECTIVE NON-CAUSATIVE COS

(a) (s-)weg i weg-i

(b) (s-)moik moik-a

(c) (s-)'oam 'oam-a

$\begin{array}{ll}\text { CAUSATIVE COS } & \\ \text { weg-i-(ji)d } & \text { 'red' } \\ \text { moik-a-(ji)d } & \text { 'soft' } \\ \text { 'oam-a-(ji)d } & \text { 'yellow' }\end{array}$

(4) Warlpiri (Hale \& Keyser I998: 93) NOUN NOUN-CAUSATIVE COS

(a) wiri wiri-jarri-

(b) maju maju-jarri-

\section{CAUSATIVE COS}

wiri-ma- 'big'

maju-ma- 'bad'

The data in (3)-(4) show that in O'odham and Warlpiri, while words denoting property concept states and their related changes of state are based on the same root, they are not morphologically identical. In these languages there is morphology that signals the difference between the word denoting the state and the COS-denoting words. Further, in these languages, property concepts are said to be lexicalized as either nouns or adjectives. By way of some kind of morphological process, then, a verb denoting a change of state is derived from the property concept denoting adjective/noun.

In languages where property concepts are lexicalized as verbs, however, the situation is often different. In such languages, it is not infrequently the case that words denoting states and words denoting changes of state share the same phonological shape, with no morphology signaling the difference between a state and a change of state denotation. The data in (5) from Tongan illustrate this point. ${ }^{2}$

(5) Tongan

(a) 'Oku loloa ho 'ulu.

IMP long your hair

'Your hair is long.'

(b) 'Oku loloa vave ho 'ulu.

IMP long fast your hair

'Your hair is quickly getting long.'

While loloa 'long' in (5a) has a stative denotation, loloa 'become long' in (5b) has a change of state denotation. In contrast to the situation in languages like Warlpiri and O'odham, there is no morphology that signals this fundamental difference in meaning. Also, in contrast to the situation in these languages, in Tongan, words like loloa that denote property concept states are lexicalized not as nouns or adjectives, but as verbs (Churchward I953). Koontz-Garboden \& Levin (2005) and Koontz-Garboden (2005) show

[2] The following abbreviations are used in the glosses of Tongan throughout the paper: ABS: absolutive case; DEF: definite; DEMONST: demonstrative; ERG: ergative case; IMP: imperfective aspect; PERF: perfective aspect; PRFCT: perfect aspect; PRSNTNL: presentational marker. 
that the same kind of relationship between property concept state-denoting words and their change of state counterparts, where the same word names both a state and a change into that state, holds not only in Tongan, but in many other languages in which property concepts are lexicalized as verbs. The empirical observation that has emerged from these investigations is stated in (6).

(6) When a single lexical item $\gamma$ is polysemous between a state and a change of state denotation, $\gamma$ belongs to the lexical category verb. (KoontzGarboden 2005: 97)

Koontz-Garboden (2005: I03ff.) gives an analysis of this generalization that appeals to the idea that only verbal lexemes can have COS denotations. It follows from this that a single lexeme, only if categorized as a verb, can have both a state and a change of state denotation. In contrast, a statedenoting lexeme lexicalized as an adjective or a noun cannot also have a change of state denotation, since only verbal lexemes can denote changes of state.

In what follows, I explore in more detail languages of the type where a single word is polysemous between a state and a change of state meaning by way of a case study of Tongan. While Koontz-Garboden \& Levin (2005) and Koontz-Garboden (2005) have shown that languages in which property concepts are lexicalized as verbs often show a state/COS polysemy, they undertook no detailed examination of any of the languages involved, leaving it an open question how it is that these meanings are related to one another in such languages. It is unclear, for example, if such languages have zero morphemes deriving COS lexemes from state lexemes, if one meaning is coerced from another, if the right analysis is one of polysemy, or even separate lexical entries, to mention some of the possible analyses. In languages like O'odham and Warlpiri, as shown above, there is a morpheme marking the derivation of a COS lexeme from a property concept denoting lexeme. I show that such a derivation is lacking in Tongan. Instead, COS meaning is derived pragmatically via a process known as coercion (Moens \& Steedman I988, Jackendoff I997, de Swart I998, Zucchi 1998, Michaelis 2004) - it is only in a particular sentential context that an otherwise state-denoting predicate takes on COS meaning.

This finding has implications both for typology and for theories of event structure. Typologically, there turn out to be more ways than anticipated that languages can relate states and changes of state to one another. Languages do this not only morpholexically (as in Warlpiri and O'odham), but pragmatically as well. Further, this possibility correlates with another typological parameter - how states are lexicalized. It is only in languages where property concept states are lexicalized as verbs that a single word can be used with both state and COS meaning (Koontz-Garboden \& Levin 2005, Koontz-Garboden 2005). The facts also have consequences 
for theories of event structure, which have not generally recognized coercion as a mechanism for the construction of these types of meanings. I argue that failure to recognize this process results in a loss of generalization - the Tongan facts require a fundamentally different kind of analysis from that required for Warlpiri and O'odham, for example. Theories of event structure, I suggest, need to be rethought in light of the Tongan data.

In discussing aspectual notions such as state and state change in the context of Tongan, I necessarily draw on theoretical machinery from the aspect and event structure literature, which I briefly review in the section that follows. Using these tools, I then lay out the relevant facts of Tongan, following this discussion with arguments for a coercion analysis of the derivation of COS meaning. I then go on to argue for two kinds of constraints on the otherwise overly powerful process of coercion: monotonicity and mapping rules that dictate what types of meanings can be denoted by what types of lexical category. This is followed by discussion of implications of the facts of Tongan for typology and for theories of event structure.

\section{THEORETICAL BACKGROUND}

In this section I discuss the theoretical notions I make use of in the remainder of the paper. I do this in particular by clarifying what is meant by a change of state, drawing on work by Dowty (1979) and by adopting a system of lexical semantic representation in the form of event structures based on work by Rappaport Hovav \& Levin (1998). I also make clear the distinction between situation and viewpoint aspect and briefly discuss how derivational operations alter the kind of lexical meaning at issue in this paper.

\section{I Event structure, states, and changes of state}

\section{I.I Dowty's theory of BECOME}

Dowty (1979: 73ff.), building on von Wright (1963, 1968), proposes a theory of change embedded in the context of a larger program of lexical decomposition. His idea is that there is a particular operator, BECOME, that forms part of the lexical semantics of COS predicates. Like other operators proposed in decompositional theories, this operator can combine with others to generatively build the meanings of words in the lexicon (or the syntax, in generative semantics and certain modern Chomskyan theories), so that the BECOME operator in combination with a stative proposition yields a COS meaning. This is represented schematically in (7).

(7) $[$ BECOME $[\mathrm{x}<$ STATE $>]]$

As regards of the referential meaning of a word with a decompositional representation like (7), Dowty ultimately settles on the interval-based 
truth conditions in (9) for changes of state, with the relevant definitions in (8). ${ }^{3}$

(8) Interval-based semantics for BECOME (Dowty I979: I39f.)

(a) Interval

Let $T$ be the set of real numbers. Let $\leqslant$ be the standard dense linear ordering of $T$. I is an interval iff $I \subset T$ and for all moments $t_{1}, t_{2}, t_{3}$, if $t_{1}, t_{3} \in I$, and $t_{1} \leqslant t_{2} \leqslant t_{3}$, then $t_{2} \in I$.

(b) Initial and final bound (simplified)

$t$ is an initial bound for $I$ iff $t$ is the last moment just before $I$. Final bound is defined similarly.

(9) Interval-based truth conditions for BECOME (ibid.)

$[\mathrm{BECOME} \phi]$ is true at $I$ iff there is an interval $J$ containing the initial bound of $I$ such that $\neg \phi$ is true at $J$ and there is an interval $K$ containing the final bound of $I$ such that $\phi$ is true at $K$.

In less formal terms, for Dowty, a change in a state $\phi$ has taken place if $\neg \phi$ holds at the beginning of an interval over which the change is evaluated and $\phi$ holds at the end of that interval.

\section{I.2 Event structure representations}

The event structures (on which see Rappaport Hovav \& Levin I998) in (Io) encode the basic units of meaning of interest in the context of the discussion below - states, activities, and changes of state. The last of these can vary significantly in their degree of complexity, (IOc) and (IOd) both being changes of state, the former intransitive and the latter transitive.

(Io) Some event structure templates (Rappaport Hovav \& Levin I998: I08)

(a) $[\mathrm{x} A C T<M A N N E R>]$ (activity)

(b) $[\mathrm{x}<\mathrm{STATE}>]$ (state)

(c) $[\mathrm{BECOME}[\mathrm{x}<\mathrm{STATE}>]]$ (non-causative COS)

(d) $\left[\left[\mathrm{x} \mathrm{ACT}_{<M A N N E R>}\right] \mathrm{CAUSE}\right.$ $[\mathrm{BECOME}[\mathrm{x}<\mathrm{STATE}>]]] \quad$ (causative COS)

There are a couple of basic features of the simple ontology in (IO) that should be highlighted. First, the basic building blocks are activities (Ioa) and states (Iob), which are the primitive notions corresponding to the semantic content of all event structures. Second, the state- and activity-based primitives are not

[3] A bit more has to be said to get (Dowty I979) theory to properly capture the variable telicity of degree achievements (e.g. cool, darken) (Dowty I979: 88). Since nothing I will say hinges on telicity (and since it is somewhat orthogonal to change of state - Rappaport Hovav \& Levin 2002), I adopt Dowty's theory, as it makes the discussion more straightforward. I believe my results could likely be recast in Hay et al.'s (I999) and Kennedy \& Levin's (2002) framework in which the existence of atelic changes of states follows automatically from the idea that telicity is a consequence of the degree of boundedness of a change. If the change is bounded, the predicate is interpreted as telic; if unbounded, it is then atelic. 
reducible to one another. ${ }^{4}$ This fact plays an important role in my analysis below. Third, more complex event structures are generated by combining operators like CAUSE and BECOME with the state and activity primitives. Indeed, this is how the event structures corresponding to non-causative (IOc) and causative (Iod) changes of state are constructed. The BECOME operator is responsible for adding COS semantics, while the CAUSE operator adds causative semantics, part of which includes the introduction of a causing subevent. Finally, following Rappaport Hovav \& Levin (I998: I03) and Koontz-Garboden $(2005,2007)$, I assume that event structure representations are constructed monotonically. The idea is that while meaning, in the form of event structure operators, can be added to an event structure as a consequence of word formation processes for example, meaning may not be removed. I call this the Principle of Monotonic Composition, as stated in (II).

\section{The Principle of Monotonic Composition (PMC)}

Word meaning is constructed monotonically on the basis of event structure constants and operators.

The PMC makes predictions about how the meanings of words can expand and contract (see Koontz-Garboden 2007 for detailed discussion). In the domain under investigation here, the relationship between property concept states and their non-causative COS counterparts, the PMC makes an especially interesting prediction - non-causative changes of state can be derived from states, but not vice versa, as the latter derivation would be a non-monotonic one. This can be seen clearly by considering the event structure representations laid out in (IO) for states and non-causative changes of state. These are repeated in (I2) and (I3).

Event structure template for property concept state $[\mathrm{x}<\mathrm{STATE}>]$

(I3) Event structure template for non-causative COS [BECOME $[\mathrm{x}<\mathrm{STATE}>]]$

[4] Though much recent research has been carried out on the assumption that activities are not reducible to states, this is not how Dowty's (1979) system is set up. The motivation for the departure of current approaches to the decomposition of activities from that of Dowty lies in the observation that, unlike accomplishments and achievements, there is no clear sense in which activities entail states. Foley \& Van Valin (1984), for example, observe that 'it is difficult to imagine, for example, what kind of truly stative predicate could underlie verbs like roll, fall, run, and walk' (Foley \& Van Valin 1984: 38 ). Similar comments are made in Van Valin \& LaPolla (I997: I03-IO4). This criticism is implicit in the analysis of Rappaport Hovav \& Levin (1998), laid out above, under which activities are not reducible to states. Lin (2004) also treats states and activities as primitives, with neither derivable from the other. Though further work should be carried out on this issue, the assumption that activities are not decomposable into states seems to be uncontroversial. 
While a BECOME operator could be added to a stative event structure template in order to derive a change of state, the reverse could not happen. This would involve the deletion of a BECOME operator, inconsistent with the PMC. The idea, then, is that any derivation can only be meaningadding.

For the event structures in (Io) to really mean anything, there must be truth conditions associated with each of the operators. Particularly important for the discussion of the Tongan facts are BECOME, ACT, and STATE. ${ }^{5}$ The truth conditions of BECOME, the operator responsible for the semantics of change, have already been given in (9). This leaves the STATE and ACT operators. STATE is really more a variable than an operator, standing in for various primitive stative notions that predicates can be built on. Still, for the discussion of how states and changes of state are related, it is just as important to understand what it means to be a state as it is to understand what it means to be a COS. Assuming the definition of interval in (8a), abbreviated as $I$, I follow Dowty in taking the following property to hold of states (Dowty 1979: 166, based on Taylor 1977).

(I4) If $\alpha$ is a stative predicate, then $\alpha(\mathrm{x})$ is true at all moments within $I$. (Dowty 1979: I66)

An important point worth mentioning with respect to (I4) is that although the size of the interval at which the truth of a stative predicate may span more than one moment, it need not; there are states that can be evaluated at a single moment. This can be seen by considering a sentence like (I5).

\section{(I5) Kim knows Sandy.}

The truth of (I5) can be evaluated simply by determining whether at the interval $I$ it is true that Kim knows Sandy. This truth can be determined even if the interval contains only a single moment $t$. What it takes, then, to evaluate the truth of a stative predicate differs markedly from what it takes to evaluate the truth of BECOME, which, though evaluated at a single interval, minimally requires that that interval consist of two moments, one at which $\neg \phi$ holds and one at which $\phi$ holds (see (9)). A further characteristic differentiating states from changes of state is the nature of the interval at which they are evaluated - for states, the stative predicate must be true at all moments in the interval at which it is evaluated. Thus, while states are characterized by a complete lack of change at the interval at which they are evaluated, the reverse is true for changes of state, as can be seen in the truth conditions for BECOME in (9).

Concerning ACT, important in the discussion below is the fact that like BECOME, but unlike STATE, its truth can be evaluated only at intervals

[5] The CAUSE operator does not play a role in the discussion below, and I therefore leave it undefined here. 
larger than one moment (Dowty 1979: I66). This follows from Dowty's (I979: I66) postulate in (I6), also adapted from Taylor (I977).

(I6) If $\alpha$ is an activity verb, then if $\alpha(\mathrm{x})$ is true at $I$, then $\alpha(\mathrm{x})$ is true for all subintervals of $I$ which are larger than a moment. (Dowty I979: I66)

That (I6) is valid is also obvious when one thinks about what it takes to evaluate the truth of an activity such as the one in (I7).

(I7) Kim walked.

The truth of (I7) can only be determined at an interval containing more than one moment. Dowty demonstrates this by considering an activity, like walking, as presented by a motion picture, frame by frame (i.e. moment by moment). One cannot establish that Kim is walking simply by looking at one frame of a movie (Kim might simply be standing, for instance). This can only be done by looking at more than one moment and establishing that there has been a change, e.g. in location from one moment to another.

What I assume, then, is that whether or not a verb denotes a state, activity, or change of state is a property of its event structure template. The derivation of a change of state from a state involves an alteration in event structure, the same level of representation at which situation aspect is calculated.

\subsection{Viewpoint aspect}

Situation aspect is crucially different from the level at which viewpoint aspect is calculated, which I assume, in accordance with numerous studies (Comrie 1976, Olsen 1996, Smith 1997, Sasse 2002), to be a separate level. Viewpoint aspect serves to present situations, with their own particular aspectual properties as discussed above, from different perspectives relative to the time of reference, e.g. as completed or ongoing relative to that time. In Reichenbach's (I947) terms, viewpoint aspect serves to establish the relationship between the event (situation) time and the reference time. Some languages mark such distinctions morphologically, as in Spanish, for example, where a verb presented in the imperfective viewpoint (I8a) is marked in a way contrasting with its presentation in the perfective viewpoint ( $18 \mathrm{~b}$ ).

(I8) (a) Juan cant-aba.

Juan sing-IMPF

'Juan was singing.'

(b) Juan cant-ó.

Juan sing-PERF

'Juan sang.'

Verbs marked with the imperfective viewpoint, like (I8a), present the situations they name as ongoing, while those marked with the perfective, like (I8b), present the situations they name as completed. More formally, the 
perfective/imperfective contrast can be characterized as in (19) and (20), taken verbatim from Smith (1997: I27) with her TIMES corresponding to Dowty's (I979) MOMENTs; the idea is simply that a situation, regardless of its type (state, change of state, activity), is viewed as unbounded without endpoints in the imperfective (I9), and as bounded with endpoints in the perfective (20).

(19) Imperfective viewpoint (Smith 1997: I27)

The viewpoint Imperfective is located at interval I; with the condition that for all times $t$ in I, an interval of the situation S obtains, and there is no time at which the endpoints of S obtain.

(20) Perfective viewpoint (Smith 1997: 127)

The viewpoint Perfective is located at interval I; with the condition that the situation $\mathrm{S}$ obtains at $\mathrm{I}$, and there are times $\mathrm{t}_{i}, \mathrm{t}_{n}$ included in $\mathrm{I}$ at which the endpoints of S obtain.

In addition to these two kinds of viewpoint aspect markers, another that plays a role in the discussion below is the significantly more complicated PERFECT. Analyses of perfect constructions in English and other languages typically identify several different uses (Comrie 1976, Mittwoch I988, Michaelis I994, Kiparsky 2002, Portner 2003). Though each author may give them slightly different names, the uses are generally the same. Among the readings identified by Kiparsky, for instance, are those in (2I).

(2I) Readings of the perfect (Kiparsky 2002)

(a) Existential: Fred has visited Paris several times.

(b) Universal: I have known him since I960.

(c) Resultative: The police have probably caught the suspect by now.

(d) 'Hot news': Archduke Ferdinand has been assassinated in Sarajevo. [June 28, I9I4]

Not all of these readings are available for all kinds of predicates; indeed, there are restrictions on readings of the perfect to predicates of different (situation) aspectual classes. For example, the universal reading (also called the CONTINUATIVE) is available only for stative predicates (Portner 2003:46I). Similarly, the resultative reading, which names a state that comes about as the result of some event, is possible only with accomplishment and achievement predicates (Mittwoch I988, Kiparsky 2002). Of particular interest in the discussion that follows will be the resultative reading of the perfect (2Ic), whose meaning I take to be (22), where the intervals $\mathrm{E}$ and $\mathrm{R}$ stand for Reichenbach's (1947) event time and reference time, respectively.

(22) Characterization of the resultative reading of the perfect

A perfect in the resultative reading denotes a state $\phi$ which is true at an interval $\mathrm{R}$ iff there is an interval $\mathrm{E}$, the final moment in $\mathrm{E}$ is the initial moment in $\mathrm{R}$, and $\phi$ is false at the initial bound of $\mathrm{E}$ and true at the interval $\mathrm{R}$. 
From the truth conditions in (22), it follows that prior to the interval at which the state denoted by a resultative perfect can be said to be true, there must be a change into that state, since the truth conditions are such that at the initial bound of the event time interval $\mathrm{E}$, the state is false, but is true at the reference time interval $\mathrm{R}$ (cf. the truth conditions for BECOME in (9)). What the perfect marker (in its resultative guise) does is to take as an argument a verb denoting such an event, mapping it into its result state. This can be formalized as in (23), drawing on Davidsonian event semantic representations, where $e$ is the Davidsonian event variable and $s$ is the Davidsonian state variable (with change of state and activity situations being kinds of events, and state situations being states; Parsons 1990).

(23) Resultative perfect operator (simplified, from Deo 2006) $\lambda P \lambda s \exists e[P(e) \wedge R E S U L T(e)=s]$

The idea is that the resultative perfect operator takes an eventive predicate as its argument, mapping that predicate into a state that holds as a result of the event. $^{6}$

\subsection{Inchoative morphemes}

Words denoting states and words denoting non-causative changes of state are often related to one another via some sort of derivational morpheme that attaches to the word denoting the state, changing it into a word denoting a change of state. This sort of behavior was seen for O'odham in (3) and Warlpiri in (4). The Quechua suffix - ya is another clear example of such a morpheme.

(24) Quechua (Weber 1989, Weber et al. 1998)
(a) hatun 'big'
(b) hatun-ya 'become big'

Affixes like Quechua -ya are commonly called INCHOATIVE affixes in both the descriptive and formal literature. The defining feature of a so-called 'inchoative' marker is that it affixes to a word denoting a state to give rise to a word denoting a non-causative change of state. In the terms discussed above, it might be said that the $-y a$ suffix marks the addition of a BECOME operator to the event structure.

(25) (a) hatun $[\operatorname{big}(\mathrm{x})]$

(b) hatun-ya [BECOME [big(x)]]

[6] This discussion oversimplifies the semantics of the perfect. A more thorough discussion would need to confront the contrast between resultant states and target states (Parsons I990, Kratzer 2000), and how the various readings of the perfect are generated, both in Tongan and generally. These are issues that are somewhat tangential to the results presented below, and in any event extend far beyond the scope of this paper. 
Although $-y a$ changes a state-denoting word into a COS-denoting word, it does this by altering the situation aspect, doing nothing to the viewpoint aspect. This can be seen in the examples in (26), where a -ya suffixed word is presented from different viewpoints, indicated by the viewpoint marking on the verbs.

(26) (a) Ushajpämi yana-ya-cäcu-sha. completely black-INCH-COMPLETE-3PERFCT 'It had become completely black.' (Weber et al. I998: 6I8)

(b) Hatun-ya-n. big-INCH-3PRES

'He/She/It becomes big.' (Weber I989: 36)

While the $-y a$ suffixed word in (26a) appears in the context of the completive viewpoint aspect marker and the event is therefore viewed in its entirety, (26b) is in the present tense, a kind of imperfective viewpoint, and the translation given by Weber suggests that the event named by the sentence is viewed as ongoing. These sentences, then, illustrate the independence of the situation aspect marker $-y a$ from viewpoint aspect marking.

Though all languages presumably have non-causative COS meanings, my claim is that these meanings are derived in fundamentally different ways from one language to another. Thus, it is important for the remainder of the paper that a distinction be made between the morphology which marks a particular meaning and that meaning itself. So, while so-called INCHOATIVE markers, such as Quechua - $y a$, by definition mark a noncausative COS meaning, non-causative COS meaning does not always arise as the result of the presence of an inchoative marker, as will be seen for Tongan.

\subsection{What kind of morphological process does the inchoative morpheme mark?}

In their discussions of the relationship between morphology and lexical semantics, both Sadler \& Spencer (I998) and Levin \& Rappaport Hovav (1998) make a distinction between two types of meaning-altering morphological derivation - what Sadler \& Spencer (I998: 208) call MORPHOLEXICAL processes and MORPHOSYNTACTIC processes. While morpholexical processes are always meaning-changing and have the effect of creating a new lexeme, morphosyntactic processes do not necessarily change the meaning of a predicate in such obvious ways, leading merely to different forms of the same lexeme (Sadler \& Spencer 1998: 223).

Taking the distinction between morpholexical and morphosyntactic processes just a step further, while morpholexical processes are operations on event structure (or lexical conceptual structure, as Sadler \& Spencer I 998 and 
Levin \& Rappaport Hovav 1998 call it), morphosyntactic processes are operations on a level of representation much closer to syntax. As both Sadler \& Spencer (1998) and Levin \& Rappaport Hovav (1998) observe, there seem to be two kinds of morphology. Some morphology marks fundamental changes to the meaning of a predicate, creating a new lexeme. Other morphology marks more superficial changes less relevant to meaning, and more relevant to morphosyntax. Of concern in the present context, then, is whether the derivation from a state to a change of state in languages like Quechua is a morpholexical or a morphosyntactic process. I suggest that it is a process of the former type, since it alters truth conditional and lexical meaning in fundamental ways and since it does not alter valence; both property concept states and non-causative changes of state are predicates that take a single argument. Knowing that the function of affixes like Quechua - $y a$ - is to effect a meaning change in event structure helps make the contrast between languages like Quechua and languages like Tongan, which lacks any such morpheme, sharper.

\section{A language with coercion of COS meaning: Tongan}

In contrast to languages like Warlpiri, O'odham, and Quechua, there are also languages where the generation of a non-causative COS meaning is achieved without any morphological marker signaling the derivation of a COS event. It is the surrounding context that is responsible for determining whether a property concept word is interpreted as a state or a change of state. Tongan is one such language. ${ }^{7}$ In this section, I discuss several syntactic contexts that force either a state or a non-causative COS interpretation in this language. I begin with some background on Tongan more generally. Following this, I give facts illustrating several different syntactic and semantic contexts that force either a state or a COS interpretation. I then develop an analysis of these facts in section 4, discussing constraints on coercion, the proposed analysis, in section 5 .

\section{I Some basic facts of Tongan}

Tongan is an ergative VSO Polynesian language spoken in the South Pacific by approximately I03,000 people as of 1987, according to Ethnologue.

Among the most important facts about Tongan relevant for the present discussion is that it has preposed clitic-like viewpoint aspect markers. These aspect markers are illustrated with a verb denoting an event of speaking in (27).

[7] Data from a number of other such languages are reviewed in Koontz-Garboden (2005). 
(27) (a) 'Oku lea 'a Pita. IMP speak ABS Pita.

'Pita speaks.' (Churchward I953: 37)

(b) Na'e lea 'a Pita. PERF speak ABS Pita. 'Pita spoke.'

(c) Kuo lea 'a Pita. PRFCT speak ABS Pita 'Pita has spoken.'

While the 'oku sentence in (27a) is viewed as ongoing, the na' $e$ sentence in $(27 \mathrm{~b})$ is bounded, and viewed with endpoints. The $k u o$ sentence in $(27 \mathrm{c})$, for its part, situates the event as over, but still with some relevance to the present time, much like the so-called 'current relevance' property characteristic of certain readings of the perfect aspect (Mittwoch I988, Binnick 199I, Kiparsky 2002, Portner 2003). Indeed, in the terms discussed in section 2.2, kuo is a perfect marker, with 'oku being a marker of the imperfective viewpoint, and $n a^{\prime} e$ a marker of the perfective. The same conclusions can be discerned from Churchward's (1953: 38ff.) careful description of these markers, though he lacked the modern terminology.

An additional fact of Tongan that plays an important role in the discussion below is that, like other Polynesian languages, it seems that in Tongan there is not much motivation for positing a contrast between verbs and adjectives. The similarity in morphosyntactic behavior between eventdenoting words and property concept denoting words has been noted at least since Churchward, who observes on the basis of data like (28) that 'in Tongan, though not in English, a predicative adjective is construed exactly as if it were a verb' Churchward (1953: 20).

(28) (a) $\mathrm{Na}^{\prime} \mathrm{a}$ ku masiva.

PERF I poor

'I was poor.' (Churchward I953: 20)

(b) $\mathrm{Na}^{\prime} \mathrm{a} \mathrm{ku}$ 'alu.

PERF I go

'I went.'

(ibid.)

Another diagnostic often used to distinguish between verbs and adjectives is the behavior of property concept denoting words and event-denoting words in attributive constructions. Here too, a clear distinction between these types of words does not surface in Tongan, as Churchward also noted. Indeed, both event words and property concept words can attributively modify nouns.

(29) (a) ha me'a lahi

a thing big

'a big thing' (Churchward I953: 190) 
(b) ha tangata tau

a man fight

'a fighting man, soldier' (Churchward 1953: 19)

The idea that Tongan lacks a clear distinction between a class of verbs and a class of adjectives is also widely accepted in the lexical category literature. Indeed, this much generally seems to be taken for granted, presumably on the basis of data like those discussed by Churchward. The discussion of lexical categories in Tongan generally focuses more on the question of whether there is a noun-verb distinction (Tchekhoff 1984, Hengeveld 1992, Broschart 1997, Beck 2002). While I agree that there does not seem to be a distinction between verbs and adjectives in Tongan, I remain agnostic on the question of a noun-verb distinction.

Having now laid out some of the basic grammatical facts of Tongan, I turn to discussion of how it is that state and non-causative change of state meanings are generated and morphosyntactically encoded in the language.

\section{2 'Oku constructions}

In Tongan, property concept words take the same viewpoint aspect markers that event-denoting words take. When marked by 'oku, property concept words denote a state holding of the subject at the moment of reference (Reichenbach's 1947 reference (R) time), regardless of whether that moment of reference is in the past, present, or future. Examples are given in (30) (with the assumption of present time reference).

(30) (a) Ko e tepile 'oku lōloa. PRSTNL DEF table IMP long. 'The table is long.'

(b) Ko e tamasi'i' 'oku pukupuku. PRSTNL DEF boy IMP short/small 'The boy is short.'

(c) 'Oku mokomoko 'a e loki. IMP cool ABS DEF room 'The room is cool.'

(d) Ko Mele 'oku vaivai. PRSTNL Mele IMP old/weak 'Mele is old.'

Crucially, it seems that sentences such as those in (30) can only denote states. My consultant explicitly rejects attributing change of state meanings to them. In order to use an 'oku construction to talk about an ongoing change of state, adverbial modification is required, as in (3IC), in which case the 
verb names a change of state from the ongoing viewpoint (i.e. without its endpoints).

(3I) (a) CONTEXT: You want your hair to be five feet long, and right now it's very short, but you're letting it grow. A short time from now, it has become two feet long. At that time, someone could say ....

(b) \#'Oku loloa ho 'ulu. IMP long your hair

'Your hair is long.' NOT: *Your hair is getting long.

(c) 'Oku loloa vave ho 'ulu. IMP long fast your hair

'Your hair is quickly getting long.'

The same sort of contrast is illustrated by the data in (32) and (33) - while in the absence of any adverbial modifier the 'oku constructions in (32a) and (33a) have stative interpretations, they have COS interpretations in (32b) and (33b) in the context of a rate adverb.

(32) (a) Ko e loki ko eni 'oku mokomoko. PRSNTL DEF ROOM PRSNTL DEMONST IMP cOOl 'The room is cool.'

(b) $\mathrm{Ko}$ e loki ko eni 'oku mokomoko PRSNTL DEF rOOM PRSNTL DEMONST IMP cool vave/tuai. fast/slow 'That room cools down quickly/slowly.'

(33) (a) Ko e fa'ahinga matala'i'akau ko PRSNTL DEF kind flower PRSNTL DEMONST IMP kulokula.

red

'That kind of flower is red.'

(b) Ko e fa'ahinga matala'i'akau ko eni' 'oku PRSNTL DEF kind flower PRSNTL DEMONST IMP kulokula vave/māmalie. red fast/slow

'That kind of flower turns red quickly/slowly' (e.g. once it blooms, it changes to red in a short amount of time).

In section $4 \mathrm{I}$ explain why it is that 'oku-marked property concept words get a COS interpretation in the presence of an adverb. For the moment, the important point is that in the absence of adverbial modification 'oku marking with a property concept word gives rise to an ongoing state interpretation. To get a COS reading with these constructions, additional adverbial modification is required. This contrasts with what is observed with kuo. 


\section{$3 \cdot 3$ Kuo constructions}

While I have shown above that 'oku-marked property concepts in the absence of adverbial modification denote ongoing states, I show here that kuo-marked states denote non-causative changes of state. That is, the truth conditions of a kuo-marked state are akin to the truth conditions laid out above for the BECOME operator. In this section, I discuss some of the differences between kuo and the other viewpoint aspect markers, while at the same time laying out the facts of kuo more generally, making the case that words denoting property concepts modified by kuo have a COS meaning.

\subsection{Kuo versus 'oku and na'e}

Similar to 'oku-marked property concepts, $k u o$-marked property concepts also give rise to an inference that the state in question holds at the time of reference. This is illustrated for kuo by the data in (34), which show that one cannot have a kuo-marked property concept for which the same 'oku-marked property concept does not hold.

(34) \#Ko 'eni kuo mokomoko 'a e loki ka 'oku ikai PRSNTL this PRFCT cool ABS DEF room but IMP not mokomoko ia.

cool it

'The room cooled down, but it is not cool.'

The sentence in (34) is acceptable if the room has indeed become more cool than it was before, but has just not reached the level of coolness desired of the speaker. In any case, though, use of kuo entails that some degree of coolness has been achieved and holds at the time of reference.

In this way, both $k u o$ and 'oku contrast with na'e, which does not have this inference, and implicates that the state does not, in fact, hold any longer at the time of reference (i.e. it holds at Reichenbach's event time, but not necessarily at Riechenbach's reference time). This is illustrated by the data in $(35){ }^{8}$

(35) (a) 'Oku lōloa 'a Sione.

IMP tall ABS Sione

'Sione is tall.'

[8] It can be shown that the inference in (62c) that the state does not hold at the reference time is an implicature, since it can be cancelled, as in (i).

(i) Na'e pukupuku 'a Sione pea 'oku kei pukupuku pe ia. PERF short ABS Sione and IMP still short only ABS he 'Sione was short and he is still short.' 
(b) Kuo lōloa 'a Sione. PRFCT tall ABS Sione

'Sione has become tall (i.e. has grown tall and is presently tall).'

(c) $\mathrm{Na}^{\text {'e }}$ lōlōa 'a Sione. PERF tall ABS Sione

'Sione was tall (Sione is now dead, or has become short).'

Though they both give rise to an inference that the property concept state holds at reference time, $k u o$, in contrast to 'oku, gives rise to the additional inference that the currently holding state has come about as a result of a change, and that prior to the reference time the state did not hold. I illustrate this in the section that follows.

\subsubsection{Kuo-marked property concepts have a change inference}

Consider the case of having long hair. If Sione is introduced to Mele for the first time, and he observes that she has long hair, Sione can say something like (36b), while (36c) would be unacceptable in this context.

(36) (a) CONTEXT: Sione meets Mele for first time; observing that she has long hair, he remarks ...

(b) 'Oku loloa ho 'ulu. IMP long your hair 'Your hair is long.'

(c) \#Kuo loloa ho 'ulu. PRFCT long your hair unacceptable in context (36a)

In contrast, it might be the case that Sione already knows Mele, and at time $t$-I he sees Mele and observes that she has short hair. If Sione then runs into Mele at time $t$ and her hair has grown significantly between $t$-I and $t$, Sione might then say something like (36c), repeated in (37).

(37) Kuo loloa ho 'ulu.

PRFCT long your hair

'Your hair has grown (lengthened).'

Similarly, if Sione just randomly walks into a room and observes that there are dry clothes on the ground without having any knowledge about the state of their dryness prior to walking into the room, he must use 'oku, as in (38b). The kuo marker would be anomalous in such a context, as shown in $(38 \mathrm{c})$.

(38) (a) CONTEXT: Sione randomly walks into a room and sees that there are dry clothes on the ground. He has no knowledge about the state of their dryness prior to walking into the room. 
(b) 'Oku mōmoa 'a e vala. IMP dry ABS DEF clothes 'The clothes are dry.'

(c) \#Kuo mōmoa 'a e vala. PRFCT dry ABS DEF clothes unacceptable in context $(38 \mathrm{a})$

Something like (38c), on the other hand, is perfectly fine given a context in which Sione has some wet clothes, hangs them out on the clothesline to dry, and returns after some period of time to find that they are dry. In such a context, (38c), repeated in (39), is acceptable.

(39) (a) CONTEXT: Sione has done the laundry and has a bunch of wet clothes. He hangs them out on the line to dry while they are still wet. He leaves to go do something else and returns after some period of time, finding that they have dried in the interim.

(b) Kuo mōmoa 'a e vala.

PRFCT dry ABS DEF clothes

'The clothes dried.'

The contrast just illustrated between 'oku and kuo appears to be completely general and productive with words denoting property concepts (and indeed, it seems, with stative verbs more generally). This is not surprising in light of Churchward's description:

[kuo] represents the event or state as having happened or having come into existence, either at the present time, or at a past or a future time, as indicated by the context ... note particularly the words 'having come into existence' as indicating the fundamental meaning of kuo when a state or condition is spoken of (Churchward I953: 38, 40)

The result of kuo-marking of a property concept denoting word, then, is the same as the meaning described for BECOME above. A property conceptdenoting word marked by kuo denotes a change of state, specifically a change from $\neg \phi$ at the beginning of the interval at which it is evaluated to $\phi$ at the end of that interval (cf. (9)). It seems fair to say, then, that marking a property concept word with kuo is one way in which Tongan generates a noncausative COS meaning.

There is something peculiar about this, though, at least based on what was seen above in other languages $-k u o$ is a marker not of situation aspect, but rather of viewpoint aspect, since kuo can mark all kinds of eventualities, as discussed in section 3.I. Unlike the situation observed in Warlpiri, O'odham, and Quechua, there is no overt marking of situation aspect in Tongan, at least with non-causative changes of state based on property concepts. In this case, then, viewpoint aspect marking is used to somehow alter situation aspect. Exactly what the mechanism is that forces this is discussed in section 
section 4. For now, I turn to a final context in which a property concept word turns up with non-causative COS meaning.

\section{4 'Osi constructions}

Property concept words also have COS meaning in what I call 'osi constructions. These are constructions in which some kind of verb, whether state- or event-denoting, appears as the complement of a higher verb, 'osi, which means something like English finish (Churchward 1953: 43). An example with an eventive verb is given in (40).

(40) Kuó u 'osi tuku ange kinautolu. PRFCT I 'OSI let.go DIR them

'I have let them go.'

(Churchward I953: 43.21)

Interestingly, this verb is found not only with eventive verbs, but also with more stative verbs, among them the property concept verbs, as shown in (4I).

(4I) Kuo 'osi lōloa 'a Sione. PRFCT 'OSI tall ABS Sione

'Sione has grown tall (i.e. has finished becoming tall),

The observation of interest here is that the property concept word in (4I), lōloa has a change of state, not a stative, meaning. So, (4I) cannot mean that Sione has finished being tall and is now not tall - rather, it means that Sione has finished BECOMING tall. This restriction on interpretation holds generally for property concept words in this construction, and regardless of whether the aspectual marker of 'osi is kuo, 'oku or na'e, as the data in (42)-(44) demonstrate.

(42) Kuo 'osi viviku 'a e tauveli. PRFCT finish wet ABS DEF towel

(a) \#The towel finished being wet, i.e. is presently dry.

(b) 'The towel got wet.'

(43) Na'e 'osi viviku 'a e tauveli. NA'E finish wet ABS DEF towel

(a) \#The towel finished being wet, i.e. is presently dry.

(b) 'The towel got/had become wet.'

(44) 'Oku 'osi viviku 'a e tauveli. IMP finish wet ABS DEF towel

False in a context where towel is presently dry; true in a context where towel is presently wet.

Why and how a change of state interpretation is forced in these constructions, and a state interpretation is blocked, is investigated below in section section 4 . 
3.5 States and non-causative changes of state in Tongan: a case of logical polysemy

The initial observation of this section was that Tongan lacks a situation aspect marker that derives non-causative COS verbs from stative property concept words. In this respect, the Tongan facts contrast with what was seen for Warlpiri, O'odham, and Quechua. Taking this observation as the point of departure, I then examined how it is that Tongan encodes non-causative COS meaning based on property concepts. I observed that there seem to be several ways of doing this, and that the surrounding morphosyntactic environment seems to play a large role in determining whether the property concept word is interpreted as denoting a state or a change of state. In two of the constructions I examined, the viewpoint aspect markers play a large role in determining the correct interpretation. In all cases discussed, property concept words marked with $k u o$ denote changes of state. ${ }^{9}$ The situation with 'oku is somewhat more complicated - when an expression contains simply 'oku, the property concept word, and nothing more (other than the property concept's argument), a state meaning is generated. When a rate adverb like vave 'quickly/fast' is included alongside 'oku, however, a change of state meaning is generated. Finally, I discussed the case of the verbal complement taking verb 'osi, which has a meaning something like English finish. I showed that despite the fact that property concept words receive no viewpoint aspect marking when appearing as the complement of 'osi, they get a change of state interpretation, regardless of what aspect marker modifies the higher verb'osi.

More precisely, I believe what is going on in Tongan to be a case of LOGICAL POLYSEMY as discussed by Pustejovsky (I995: chapter 3), who makes distinctions between three different types of ambiguity. First is CONTRASTIVE AMBIGUITY, characterized by an 'arbitrary association of multiple senses with a single word' (Pustejovsky 1995:29). An example of this kind of ambiguity occurs with the lexical item bank, which can have the meaning of a side of a river or a financial institution. A more systematic type of ambiguity goes by the name of COMPLEMENTARY POLYSEMY, in which the distinct senses of a word share some sort of systematic relationship to one another. Complementary polysemy is further distinguished from contrastive ambiguity in that with the latter, only one sense is available at a time (Pustejovsky 1995: 32). With complementary polysemy, on the other hand, the distinct senses tend to have some sort of overlap with one another. The

[9] This is actually an oversimplification, as seen in section 4.3 .2 , where it is shown that adverbial modifiers can force a stative reading with $k u o$ just as they do with 'oku. 
final type of ambiguity is known as LOGICAL POLYSEMY, which Pustejovsky (1995: 28) defines as follows:

a complementary [polysemy] where there is no change in lexical category, and the multiple senses of the word have overlapping, dependent or shared meanings.

Pretty clearly, the situation with property concept words in Tongan is not a case of contrastive ambiguity. As shown by the event structure representations assumed in (IO), states and changes of state overlap with one another in meaning, since a change into a state entails the state. This overlap in meaning makes the Tongan situation at least one of complementary polysemy. Further, however, in Tongan there is no change in lexical category. To take the most obvious case, 'oku-marked property concept words denote states in the absence of a rate adverb but changes of state in the presence of such an adverb, yet there is no change in the lexical category of the property concept word associated with its modification by an adverb. This makes the situation in Tongan, then, a case of logical polysemy.

Tongan, then, unlike Warlpiri, O’odham, and Quechua, lacks a morpholexical process deriving a non-causative COS from a property concept state. This is a pattern heretofore undiscussed at any length in any strain of linguistics literature I am aware of. As I show below, the existence of this type of encoding of non-causative COS events in Tongan and the existence of this alternative pattern has interesting implications for how lexical semantics is mapped onto morphosyntax. Before turning to this topic, though, I first discuss in section 4 from a slightly more technical perspective what is going on in Tongan. The results of this section lead to a better understanding of the Tongan encoding of non-causative COS events, and as a consequence to a better understanding of what the limits on the Tongan pattern are, which are discussed in section 5 alongside their implications.

\section{How DOES TONGAN DO IT?}

In this section I propose an analysis of the Tongan facts. Within the space of possible analyses, two loom large: sense enumeration and coercion. I begin the discussion by laying out what is meant by each of these analyses. I then go on to offer arguments in favor of a coercion analysis, showing how the analysis fits with the Tongan facts.

\section{I Two possible analyses}

\section{I.I Sense enumeration}

One possible analysis of the Tongan facts would be in terms of what Pustejovsky (I995) calls SENSE ENUMERATION. The idea of this approach would 
be to simply associate multiple senses with a single word at the level of the lexicon, so that if a particular meaning is used in a particular context, it is due to that meaning having been lexically selected for use in that context.

Applied to Tongan, a sense enumeration analysis would have it that all property concept words are associated with multiple senses in the Tongan lexicon - a state sense and a change of state sense. Absent some theory about why a whole swath of the lexicon should behave so similarly, this would seem like a rather arbitrary way of dealing with the phenomenon, especially given the fact that the two meanings of interest are very closely related to one another. Aside from these conceptual considerations, however, I believe that there are empirical reasons for rejecting a sense enumeration approach. I discuss these below, but first lay out an alternative to sense enumeration.

\section{I.2 Coercion}

An alternative approach to logical polysemy, initially developed by Moens \& Steedman (I988), goes by the name of COERCION. This approach is summarized succinctly and clearly by Zucchi (1998: 350):

Let $\delta$ be a syntactic constituent of form $\left[{ }_{\alpha} \beta \gamma\right]$ and $R$ the semantic rule which forms the meanings of the constituents of type $\alpha$. If combining the meanings of $\beta$ and $\gamma$ via $R$ leads to trouble (for example, leads to inconsistency or prevents from (sic) assigning an interpretation to $\delta$ ), the speaker has the option of re-analyzing the meaning of $\beta$ or $\gamma$ (coercing the meaning of $\beta$ or $\gamma$ into a different meaning) in order to apply $R$ to form the meaning of $\delta$.

The idea of coercion is that if the meanings of two elements in an utterance conflict with one another, then a language user might find a way of repairing this conflict so that the utterance actually ends up having some sort of coherent meaning. If coercion doesn't occur in this context, the two meanings cannot compose.

Though this approach certainly sounds less stipulative than the sense enumeration approach, it is also potentially far too powerful, as Zucchi (1998), Pustejovsky \& Bouillon (I995), Hana Filip (p.c.), and no doubt others note. Because of this, coercion analyses are in danger of overgenerating, and special care has to be taken to ensure that the right kinds of constraints are placed on the process.

\subsection{Choosing between coercion and sense enumeration}

I believe that the better analysis of the logical polysemy of property concept words in Tongan is one of coercion, with the state meaning being the basic lexical meaning, and the change of state meaning being the one derived via 
the coercion process. Bare property-denoting words can be used attributively with (inherent) state meaning, as illustrated in (45). This is a context where the aspect markers needn't appear; still, a state meaning is generated.

(45) (a) Ko e fine'eiki vaivai 'oku faka'ofo'ofa.

PRSNTNL DEF woman old IMP pretty

'The old woman is pretty.'

(b) Ko e tepile lōloa 'oku faka'ofo'ofa.

PRSNTNL DEF table long IMP pretty

'The long table is pretty.'

The sentence in (45a), for example, crucially does not refer to a change into state a state of oldness; it is not ambiguous between a basic state and a change of state. It simply refers to a woman who happens to be old. This sentence might be used, for example, in a context where a person meets her for the first time, and observes that she is old. To get a COS interpretation, whereby, for example, the woman in (45) has aged, perhaps between the last time that a person saw her and the moment that s/he saw her again, a relative clause is required, as in (46), which crucially entails the use of an aspect marker, making kuo an option for use. ${ }^{10}$

(46) (a) Ko e fine'eiki kuo vaivai 'oku faka'ofo'ofa. PRSNTNL DEF wOMan PRFCT old IMP pretty 'The woman, who has become old, is pretty.'

(b) Ko e tepile kuo lōloa 'oku faka'ofo'ofa. PRSNTNL DEF table PRFCT long IMP pretty 'The table, which has become long, is pretty.'

If property concept words were polysemous, and had both state and change of state lexical entries, the facts would be expected to be otherwise, with (45) being ambiguous between the state reading that it actually has, and the change of state reading that (46) has. As observed, however, the change of state reading in (46) only arises via the use of a relative clause with kuo aspect marking on the property concept word. Based on these facts, I conclude (a) that property concept words have a single lexical meaning, and (b) that it is the state meaning.

\subsection{The coercion of states to changes of state in Tongan}

Having now argued that Tongan property concept words have only stative lexical entries, this leaves the question of how the change of state meanings are generated, in particular how it is that states are coerced to changes of

[Io] For discussion of the properties of relative clauses in Tongan, see Otsuka (2000: II6ff.). 
state in particular contexts. I approach this question by examining each of the constructions discussed above in which a change of state meaning arises. In each of these cases, I argue that it is semantic properties of lexical items in each of the constructions that forces the change of state meaning to emerge, and indeed makes a state meaning impossible in these contexts. The idea for each of these contexts, then, is that either a change of state meaning must arise or the meanings denoted by the words of the sentences cannot compose, state meaning being inconsistent with the surrounding sentential context. This is exactly the idea behind Zucchi's (1998) definition of coercion given above.

\subsection{Change of state 'oku with adverbial modifier}

As discussed above, bare 'oku constructions denote states, as shown in (47a) and (48a) (=(32a), (33a)). In contrast, however, 'oku constructions in the presence of a rate adverb denote changes of state, as shown in (47b) and (48b) $(=(32 b),(33 b))$.

(47) (a) Ko e loki ko eni 'oku mokomoko. PRSNTL DEF ROOM PRSNTL DEMONST IMP cool 'The room is cool.'

(b) Ko e loki ko eni 'oku mokomoko PRSNTL DEF ROOM PRSNTL DEMONST IMP cOol vave/tuai. fast/slow 'That room cools down quickly/slowly.'

(48) (a) Ko e fa'ahinga matala'i'akau ko eni' 'oku PRSNTL DEF kind flower PRSNTL DEMONST IMP kulokula. red 'That kind of flower is red.'

(b) Ko e fa'ahinga matala'i'akau ko eni' 'oku PRSNTL DEF kind flower PRSNTL DEMONST IMP kulokula vave/māmalie. red fast/slow

'That kind of flower turns red quickly/slowly.' (e.g. once it blooms, it changes to red in a short amount of time)

This follows from the co-occurrence possibilities of rate adverbs with verbs. In English, too, adverbs with meanings like quickly and slowly cannot occur with state-denoting words, be they verbs (49), adjectives in copular constructions (50), or adjectives in attributive constructions (5I).

(49) (a) \#Kim knew Sandy quickly. (unless COS 'come to know')

(b) \#Sandy believed Kim slowly. (unless COS 'come to believe') 
(50) (a) ??The room is quickly cool.

(b) ??Sandy's face was quickly red.

(5I) (a) *Quickly cool rooms are always located in the basement.

(b) *Sandy's quickly red face was covered in makeup, concealing his pain.

The sentences in (49)-(5I) are all unacceptable on the interpretation that the adverbs modify states. ${ }^{11}$

For some of the sentences given above, however, there are change of state interpretations, on which the sentences are fine. For example, the sentences in (49) are perfectly fine on the reading whereby, e.g. Kim came to know Sandy quickly, and Sandy came to believe Kim slowly. For these examples, as with the Tongan examples in (47)-(48), there is coercion of the stative verb to a change of state. The question to ask, then, is what it is about the combination of a stative predicate with quickly or slowly that 'leads to inconsistency' (in the words of Zucchi).

These conditions come about as a result of the meanings of states and of these adverbs, which are not compatible with one another. First, consider what quickly and slowly do in typical sentences in which they modify a change of state predicate, as they often seem to do.

(52) (a) The room cooled down quickly.

(b) The flower bloomed quickly.

(c) Kim's face reddened slowly as his mother passed around the naked baby pictures.

(d) Sandy slowly cleared the driveway, angry that her mother was punishing her for her behavior.

In the sentences in (52), the adverbs of interest modify change of state predicates, with the result that the sentences are perfectly acceptable. What quickly and slowly do as rate adverbials is to say something about the relationship between change and time, in particular about the amount of time over which the change took place. Consider how this works within Dowty's theory of change laid out in (9). What quickly and slowly do to a change of state predicate is to say something about the interval $I$ over which the change of state is defined. For example, to say, as in (52c), of Kim's face reddened that it happened slowly is to say something about the size (where size is defined as the number of moments contained in an interval) of the smallest interval $I$ containing an initial bound at which $\neg$ red is true and a final bound at which red is true. Namely, that interval $I$ must have some contextually significant size such that the reddening can be judged as having occurred

[II] I believe that some are unacceptable due to contradiction, while others are unacceptable due to ungrammaticality, in particular because adjectives, in contrast with verbs, cannot denote changes of state. I discuss this in more detail in $\S 5.2$. 
slowly. Likewise for quickly, the change of state modified by quickly must have taken place over an interval of a contextually short length.

Consider now why quickly and slowly should be unacceptable with states, which, according to Dowty, have the property in (I4). Slowly and quickly describe the rate at which a change takes place, making reference to an interval $I$ containing an initial bound where $\phi$ is not true and a final bound where $\phi$ is true; crucially, then, rate adverbials make reference to a change. As stated in (I4), states lack this characteristic, since a stative predicate evaluated at an interval $I$ must be true at all moments within $I$. The axiom in (I4) is thus truth-conditionally at odds with the definition of change in (9). The situation, then, is that quickly and slowly make reference to aspectual properties of the modified predicate that states lack; for states, there is no interval for which $\neg \phi$ is true at the initial bound and $\phi$ is true at the final bound. Therefore, an adverb of this type modifying a stative predicate will, as Zucchi says, be uninterpretable.

Given the contradiction that arises when states are modified with adverbs like quickly and slowly, there are three things that could happen: (a) the utterance could simply be contradictory, (b) the states could be coerced to activities, or (c) the states could be coerced to changes of state. If the utterance is not to be contradictory, then the last two possibilities are left. One might ask, then, why the property concept word shouldn't be coerced to an activity, rather than to a change of state. The explanation for this lies in the assumption that the Principle of Monotonic Composition (PMC) in (II) holds not only of the construction of word meaning in the lexicon, but of coercion as well.

Consider the event structures of states and activities that were given in (Io). If the PMC is assumed to hold of coercion, then a state cannot be coerced into an activity given the event structure representations in (IO), since this would involve the deletion of the STATE component of the event structure in order to make it into an activity. In contrast, coercions from states to changes of state are perfectly consistent with the PMC, since they only involve the addition of meaning beyond what is already inherent in the state-denoting word.

The English facts in (49)-(5I) are quite interesting when compared to the Tongan facts in (47)-(48). In Tongan, coercion from the property concept to the change of state is perfectly acceptable. Coercion from a state to a change of state is also acceptable in English, but only for a restricted set of words - for property concepts, which are lexicalized as adjectives in English, coercion is impossible, as shown in (5I). For other states, however, which are lexicalized as verbs in English, coercion from a state to a change of state under quickly/slowly modification is acceptable, as shown by the data in (49). In section 5.I I return to this contrast, arguing that it follows from a rule constraining the possible meanings of words belonging to different lexical categories. 


\subsubsection{Kuo constructions}

Kuo constructions likewise coerce a word otherwise denoting a state into a change of state. This is done by way of the semantics of kuo, which I believe to be that of the perfect aspect. Tongan kuo is found with all four of the readings characteristic of the perfect as laid out in (2I). This is shown by the data in (53).

(53) (a) Kuo ('osi) kulokula tu'o taha hoku fale. PRFCT 'OSI red occasion one my house 'My house has been red before (not red now).'

(Existential)

(b) Kuo loloa hoku 'ulu, talu pe mei he I980. PRFCT long my hair since and since DEF I980 'My hair has been long since I980 (still long now).'

(Universal)

(c) Kuo loloa ho 'ulu. PRFCT long your hair

'Your hair lengthened/got long.'

(Resultative Perfect)

(d) Kuo puke 'e he kau Polisi' 'a e matapule Tonga PRFCT seize ERG DEF ? police ABS DEF chief Tonga ko Sosaia Limu Me'afo'ou ... PRSNTL Sosaia Limu Me'afo'ou 'The police have seized the Chief Sosaia Limu Me'afo'ou ...'

(Taimi 'o Tonga 2/28/2004, [http://www.planet-tonga.com/tongatimes/Taimi2-24-2004/ newso8.shtml])

The important observation in the context of the present discussion is that these different readings do not all have the same morphosyntactic status. While adverbial modifiers translating to something like on one occasion and since 1980 are used to get the existential and the universal readings in $(53 \mathrm{a}, \mathrm{b})$, no adverbial modifiers are used with the resultative perfect in $(53 \mathrm{c})$, suggesting that the resultative reading is the default reading of the perfect in Tongan. Data I have elicited from my consultant suggest this to be the case - in the absence of adverbial modification, the resultative perfect reading is the one that arises by default (with the 'hot news' reading being a particular variety of the resultative, Michaelis I994, Kiparsky 2002). Further adverbial modification, on the other hand, is required to defeat the resultative perfect reading and to get the universal or existential reading.

In light of the truth conditions for the resultative reading of the perfect given in (22), and the formalization of the resultative perfect marker in (23), it is unsurprising that property concept states are coerced to changes of state with (unmarked) kuo constructions, which, consistent with their resultative perfect semantics, give rise to the inference that the state denoted by the construction is one that WAS PRECEDED BY A CHANGE INTO IT, with this change 
named by the verb that the perfect operator takes as an argument. Words naming property concept states do not name changes of state - they name states, which are true at all moments in the interval at which they are evaluated (I4), and therefore are inconsistent with change. Because of this, the resultative reading of the perfect will fail to compose with a statedenoting word. The state-denoting word can, however, be coerced to a change of state, by the addition of a BECOME operator to its event structure representation, and can thereby compose with the resultative perfect operator. This is precisely what happens with property concept words in Tongan in the context of kuo (absent adverbial markers). Either the unmarked resultative perfect meaning of kuo cannot compose with the stative meanings of property concept words, or coercion, to a change of state event, must take place. The latter is what is in fact observed, and is one of the several ways of generating change of state meanings with property concept words in the language, as seen above.

\subsection{3 'Osi constructions}

The coercion of property concept states to changes of state when appearing as the complement of 'osi can be explained by the meaning of 'osi itself, which is described concisely by Churchward as follows:

As a principal verb, 'osi means 'to be finished', 'to be over' ... As an auxiliary verb, 'osi conveys essentially the same meaning, but connects it with another verb, the principal verb before which it is placed. (Churchward 1953: 43)

The essence of 'osi, then, is that it forces the event described by its verbal complement to be completed. This requirement, in turn, presupposes that the complement itself is a predicate that CAN, in principle, be finished. I take this to minimally mean that there had to be some change, in the sense of (9), over the interval at which FINISH $\phi$ is evaluated. As has been discussed above, the truth conditions for stative verbs, of which Tongan property concept words are a particular kind, specify that states are true over the entire interval at which they are evaluated. Given this, the meaning of states is inconsistent with being finished; i.e. the syntactic construction finish $\phi$, where $\phi$ is a state, cannot be interpreted. The explanation for why verbs with finish-like meaning cannot take stative complements, then, is parallel to the explanation for why adverbs like slowly and quickly cannot modify states. Hence, this construction will be either unacceptable, or coerced to a COS.

\subsubsection{Summarizing the coercion account}

I have shown in the discussion above that the way that non-causative COS meanings based on property concepts arise in Tongan is consistent with 
coercion, as laid out in section 4.I.2. Non-causative COS meanings arise when a state-denoting word appears in a morphosyntactic context inconsistent with stativity. This happens when a stative word occurs in the context of an adverb like vave 'fast', which makes reference to a change that stative words lack. In the case of kuo, it is not the case that these constructions are always inconsistent with stative meaning; instead, the data suggest that the default reading of $k u o$ constructions is what has been called the RESULTATIVE PERFECT reading in the literature on the perfect. This is a reading that has been argued elsewhere to be inconsistent with states (Mittwoch I988, Kiparsky 2002), for reasons I have explained on the basis of the function of the perfect operator itself (in its resultative reading). A word denoting a state, then, when appearing in an unmarked kuo construction, must be coerced to a change of state meaning or else the meanings of the unmarked kuo construction and the property concept word will not be able to compose. Alternatively, if the speaker provides additional contextual information, e.g. adverbial modifiers, the kuo construction can have different readings which are consistent with states: the so-called EXISTENTIAL and UNIVERSAL readings. Finally, I have touched on the case of 'osi constructions, which seem to have the same sort of meaning as the verb finish in English. This verb resembles adverbs like quickly in requiring that its complement denote a change. In the face of this, a property concept state-denoting word appearing as the complement of 'osi must be coerced to a change of state, or else the meanings of 'osi and its complement would be unable to compose.

What all of this means, I believe, is that Tongan, unlike Quechua-type languages, actually lacks non-causative COS lexemes based on property concepts. Rather than deriving in the lexicon non-causative COS lexemes from the closely related property concept state lexeme via a morpholexical process, Tongan simply projects property concept state-denoting lexemes into syntactic structure, where their meaning can be altered to be consistent with the meanings of words in the surrounding syntactic environment.

\section{Some CONSTRAints ON ASPECTUAL COERCION}

Having seen how and why it is that property concept state-denoting words are coerced to changes of state in particular contexts, I now address the issue of how constraints might be imposed on the process of aspectual coercion, since absent such constraints, it would be expected that anything could be coerced, and there would never be meaning conflicts leading e.g. to contradiction.

\section{I Monotonicity}

In the discussion of the Tongan data above, I have assumed that the Principle of Monotonic Composition (II) is a constraint not only on the 
generation of word meaning in the lexicon, but also on the process of aspectual coercion. In this sense, monotonicity constrains the typology of state/change of state predicates not only in the lexicon, but beyond as well. So far as I am aware, applying monotonicity to coercion is a novel proposal. ${ }^{12}$ It makes several empirical predictions which help in evaluating it. I discuss some of these briefly here.

First, in the domain under study, the PMC extended to coercion predicts that there should be no language that is the converse of Tongan, i.e. a language in which property concepts are lexicalized as non-causative changes of state with the state meaning derived by coercion. As has been observed above for Tongan, determining the direction of coercion, from state to COS or vice versa, requires access to some detailed facts of how particular constructions are interpreted, more than are typically available in a standard reference grammar. This makes the proposal difficult to evaluate at the moment. Nevertheless, the prediction is clear and counterexamples are in principle detectable.

A second prediction relates to what the property concept state gets coerced to. Under the definition of coercion adopted above in section 4.I.2, coercion happens when two syntactic constituents have meanings that cannot compose with one another. The idea of coercion is simply that this incompatibility gets repaired. One can imagine, then, what kinds of repairs might take place were aspectual coercion taken NOT to be monotonic. In the domain of discussion above, there was one context where coercion was forced where not only change of state verbs can occur, but activities as well. This was the context where a property concept word appears marked with 'oku and an adverbial modifier, as in (54).

(54) (a) Ko e loki ko eni 'oku mokomoko.

PRSNTL DEF ROOM PRSNTL DEMONST IMP cool

'The room is cool.'

(b) Ko e loki ko eni 'oku mokomoko

PRSNTL DEF ROOM PRSNTL DEMONST IMP cool

vave/tuai.

fast/slow

'That room cools down quickly/slowly.'

Though adverbs like vave 'fast' and tuai 'slow' cannot modify verbs denoting states, it is not the case that they MUST modify verbs denoting changes of state. Indeed, they can also modify activities, as in (55).

[12] Work by Michaelis (2004), which has only recently come to my attention, appears to have a somewhat similar constraint on coercion, which she calls Aktionsart Preservation. 
... na'a ne lele vave atu ki honau 'apí...

PERF 3SING run quickly away to/toward their home

'... s/he quickly ran away to/toward their home ...'

[http://www.lds.org/conference/pdf/A200oto_session6.pdf]

Given this, it is possible that rather than coercing a property concept word to a change of state, adverbs like vave and tuai might instead coerce property concept words to more activity-like meanings. However, this behavior does not seem to be observed - the sentence in (54b) entails a change of state. ${ }^{13}$ Similar facts obtain in English for stative verbs in the presence of adverbs like quickly and slowly, as shown in (56).

(56) (a) These hard-bitten, experienced men and women of the world, like the children, quickly believed that they were better or worse than their colleagues, just on the basis of eye colour, and acted out their belief.

[http://www.dswark.org/news/pro79a.htm]

(b) Rob and I have been married for almost nine years and from the moment we met, we quickly knew we shared many common goals.

[http://www.morganlee.org/coping.htm]

Again, with English, as with Tongan, these stative verbs under modification of adverbs like quickly are coerced to changes of state with truth conditions as given in (9). This follows from both the PMC and from the event structure representations assumed in (IO). Assuming the event structure representations of activities and states in (IO), coercion from a state to an activity would be a non-monotonic coercion, and therefore would not be predicted to occur, given the PMC. Coercion from a state to a change of state, on the other hand, is predicted to be a possible coercion. It is therefore noteworthy that the 'oku constructions with vave/tuai modification and English stative verbs with quickly/slowly have meanings consistent with state change.

There is some evidence, then, that the PMC constrains not only morpholexical meaning generation, but coercion as well. As such, it constitutes a significant constraint on an otherwise very powerful process.

\subsection{On the mapping of meanings to lexical categories}

An additional family of constraints on coercion is those pertaining to the interface between event structure and morphosyntax. Recall the empirical observation in (6), repeated in (57).

[13] Full evaluation of this claim requires a better articulation than is presently available in the aspect literature of the differences in entailments between states and activities. This is an area in need of further research, as noted in fn 4 . Nevertheless, monotonicity makes a clear prediction in this area. 
(57) When a single lexical item $\gamma$ is polysemous between a state and a change of state denotation, $\gamma$ belongs to the lexical category verb. (Koontz-Garboden 2005:97)

Koontz-Garboden (2005) develops an analysis of the observation in (57) by constructing a theory about the mapping between event structure operators and the lexical categories of words. He begins with the idea in (58), taken from recent work by Lieber (2004).

(58) The outermost function of the skeleton [= event structure] determines the syntactic category (Lieber 2004:37)

Assuming Lieber's proposal in (58), the event structure assumptions laid out above, and the BECOME operator as a representation of change of state semantics, Koontz-Garboden makes more precise the idea that 'change of state is realized only by verbs' via the mapping rule in (59).

(59) Change of state mapping rule (Koontz-Garboden 2005: I04) $[\mathrm{BECOME} \phi] \rightarrow \mathrm{V}$

The mapping rule in (59) is read as follows: if BECOME is the highest operator in an event structure, then the word whose meaning is represented by that event structure must belong to the lexical category of verb. The empirical observation in (6), repeated in (57), follows from (59) - if a word is to be polysemous between a state meaning and a change of state meaning, then given (59) such a word must belong to the lexical category verb. Otherwise, the state word would belong to a lexical category incompatible with change of state meaning, in violation of the mapping rule in (59).

In addition to holding over lexical entries in the lexicon, the change of state mapping rule in (59) (and possibly the whole family of mapping rules to which it belongs) also constrains the process of coercion; while a stative verb can be coerced to have a COS meaning, as has been documented for Tongan, words denoting states that do not belong to the lexical category of verb cannot be so coerced. This is seen clearly in English - while verbal states can be coerced to changes of state, as shown for believe in (6oa), non-verbal states such as cool in (6ob) cannot.

(6o) (a) Kim quickly believed Sandy.

'Kim quickly came to believe Sandy.'

(COS reading possible)

(b) *Quickly cool rooms are always located in the basement.

'Rooms that cool down quickly are always located in the basement (intended reading).'

(COS reading impossible)

Both believe and cool denote states, yet while the verb believe can also have a change of state meaning (6oa), the adjective cool cannot (6ob). This observation is directly attributable to (59) being applicable to coercion. This rule allows a state-denoting word that is a verb to augment its event 
structure with the BECOME operator, but rules this out for non-verbal predicates.

In this way, then, the change of state mapping rule (and others like it) put further constraints on possible coercions.

\section{DISCUSSION AND CONCLUDING REMARKS}

Empirically, I have shown that there is a typological contrast between languages like Warlpiri, O'odham, and Quechua, that have a morpholexical derivation of a non-causative COS from a state, and languages like Tongan that lack such a process. In the latter type of language, there is crucially no morpheme, overt or covert, that derives a non-causative COS from a state. Rather, non-causative COS meaning arises as a result of the interaction of a state-denoting word with other aspectual elements in the syntactic context that are incompatible with state meaning. This finding has implications both for theories of event structure, and for language typology more generally.

The fact that there are languages like Tongan that crucially lack morpholexical processes to get a non-causative COS meaning from a state meaning has implications for any theory of event structure that localizes meaning formation at a single level of representation (whether in the lexicon as in Rappaport Hovav \& Levin 1998 or in the syntax as in Hale \& Keyser 2002 and Baker 2003). The theories of Hale \& Keyser (2002) and Baker (2003) are particularly clear on this point. In these theories non-causative COS meaning arises via the movement of a state-denoting adjective to a syntactic head, causing it both to be verbal and to have COS meaning. This state of affairs is illustrated in (6I).

(6I) Derivation of a deadjectival non-causative COS verb for Hale \& Keyser

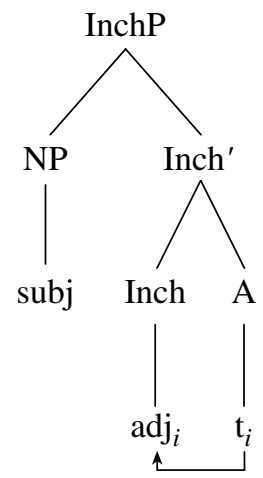

The claim of these theories, then, is that ALL LANGUAGES have the same derivational process giving rise to non-causative COS meaning. The facts of Tongan call this claim into question, as I have shown above. There is simply no morpheme, overt or covert, that could be labeled as Inch in (6I). 
How might the Tongan pattern be accounted for in a theory like that of Hale \& Keyser (2002) or Baker (2003)? One idea would be that the COS head has different realizations, for example kuo in some cases and 'osi in others. This will not work for several reasons, though. First, in the case of $k u o$, I have shown that depending on the surrounding syntactic context, kuo constructions with property concept words have either a state or a change of state meaning, so it clearly cannot simply be the case that kuo is a realization of the COS head. The same sort of problem arises with the 'oku constructions - in some cases they denote states, in other cases they denote changes of state.

Another possibility is that the COS head is simply null in Tongan. While I believe that there are cases where null morphemes may be well-motivated, I do not believe that the Tongan facts warrant such an analysis. Assuming a null COS morpheme in Tongan would leave unanswered the question of why the generation of COS meaning systematically co-varies with the appearance of other elements in the sentence that crucially require COS meaning. Further, such an analysis would also predict that 'oku and kuo constructions should be ambiguous between state and COS meanings, something which has been seen not to be the case above. They each have their own default interpretations; it is only in the presence of modifiers inconsistent with the default interpretations that alternative readings arise. The null morpheme analysis leaves these facts unexplained.

A further implication for theories of event structure arising from the discussion above is that such theories need a way to express the idea that words of certain lexical categories are consistent with certain meanings, while others are not (as with the case of change of state meaning and verbal categorization). So far as I am aware, outside of the functionalist literature (especially in the work by Givón 1984), the idea that meaning and lexical category have some sort of intimate relationship has not been taken very seriously (though see Lieber 2004). The facts discussed above suggest that they are in fact quite closely tied together, and that there are important typological generalizations to be made concerning the kinds of meanings that words belonging to various lexical categories can denote.

The results of the case study of Tongan, then, have two important implications for theories of event structure. First, such theories need a way of dealing with the generation of meaning outside of the lexicon - what some languages do morpholexically, other languages may do pragmatically, via processes of coercion, for example. Future work on theories of event structure should address this typological difference. Secondly, theories of event structure need a way of capturing the generalization that certain meanings are expressible only by members of certain lexical categories. As I discussed, this is tied to the possibility of generating COS meaning outside of the lexicon via coercion - only words belonging to the lexical category of verb can denote changes of state. Because of this, only in languages where states 
are lexicalized as verbs will we find relationships between state and change of state meaning as observed in Tongan. In this way, there is an intimate link between lexical category variation and the mechanism for deriving words naming non-causative COS events. Only in languages where states are lexicalized as verbs is coercion an option. This is an important generalization that theories of the event structure-morphosyntax interface should seek to capture. Outside of the present work, so far as I am aware, there is no formal theory that addresses this issue.

Typologically, I have shown that there exist languages that systematically use coercion processes for the derivation of non-causative COS meanings based on property concepts, and that this possibility correlates with another typological parameter - whether or not property concepts are lexicalized as verbs (as in Tongan) or not (as in languages like Quechua, Warlpiri, and O'odham). Prior to this discussion of Tongan, it was not clear from reading the typological or formal literature that Tongan-type languages existed, most likely due to the fact that little typological work has been carried out anyway on the relationship between state and change of state predicates. The fact that such languages do exist raises new questions about the relationship between other types of predicates in other languages. For example, the results raise the question whether there might be a similar contrast between languages that use coercion for the causative/inchoative alternation and languages that use (more familiar) morpholexical processes. There certainly do exist languages in which the causative/inchoative alternation is not morphologically marked (languages as familiar as English and as unfamiliar as Jalonke, according to Lüpke 2005: chapter 5), and it is certainly possible that the same processes at work in the derivation of changes of state in Tongan may be at work in the causative/inchoative alternation for at least some of these languages. All of these questions, I believe, suggest fruitful areas for future research.

\section{REFERENCES}

Alexiadou, A. \& Anagnostopoulou, E. (2004). Voice morphology in the causative-inchoative alternation: evidence for a non-unified structural analysis of unaccusatives. In Alexiadou, A., Anagnostopoulou, E. \& Everaert, M. (eds.), The unaccusativity puzzle: explorations of the syntax-lexicon interface. Oxford: Oxford University Press. II4-I36.

Baker, M. C. (2003). Lexical categories: verbs, nouns, and adjectives. Cambridge: Cambridge University Press.

Beck, D. (2002). The typology of parts of speech systems: the markedness of adjectives (Outstanding Dissertations in Linguistics). New York: Routledge.

Binnick, R. I. (I99I). Time and the verb: a guide to tense and aspect. Oxford: Oxford University Press.

Broschart, J. (1997). Why Tongan does it differently: categorial distinctions in a language without nouns and verbs. Linguistic Typology I. I23-I65.

Churchward, C. M. (1953). Tongan grammar. London: Oxford University Press.

Comrie, B. (1976). Aspect. Cambridge: Cambridge University Press.

Croft, W. (1990). Possible verbs and the structure of events. In Tsonatzidis, S. (ed.), Meanings and prototypes. London: Routledge. 48-73. 


\section{ASPECTUAL COERCION AND CHANGE OF STATE PREDICATES}

Deo, A. (2006). Tense and aspect in Indo-Aryan languages: variation and diachrony. Ph.D. dissertation, Stanford University.

Dixon, R. (1982). Where have all the adjectives gone? and other essays in semantics and syntax. The Hague: Mouton.

Dowty, D. (I979). Word meaning and Montague grammar. Dordrecht: Reidel.

Embick, D. (2004). On the structure of resultative participles in English. Linguistic Inquiry 35. $355^{-392 .}$

Foley, W. A. \& Van Valin, R. D. (1984). Functional syntax and universal grammar. Cambridge: Cambridge University Press.

Givón, T. (1984). Syntax: a functional-typological introduction. Amsterdam: John Benjamins.

Hale, K. L. \& Keyser, S. J. (I998). The basic elements of argument structure. In Papers from the UPenn/MIT Roundtable on Argument Structure and Aspect (MIT Working Papers in Linguistics 32). 73-II8.

Hale, K. L. \& Keyser, S. J. (2002). Prolegomenon to a theory of argument structure. Cambridge, MA: MIT Press.

Haspelmath, M. (I993). More on the typology of inchoative/causative verb alternations. In Comrie, B. \& Polinsky, M. (eds.), Causatives and transitivity. Amsterdam: John Benjamins. $87-\mathrm{I} 20$.

Hay, J., Kennedy, C. \& Levin, B. (I999). Scalar structure underlies telicity in 'degree achievements'. In Proceedings of SALT 9. Ithaca, NY: Cornell Linguistics Circle. I27-I44.

Hengeveld, K. (1992). Non-verbal predication: theory, typology, diachrony. Berlin: Mouton de Gruyter.

Jackendoff, R. (I997). The architecture of the language faculty. Cambridge, MA: MIT Press.

Kennedy, C. \& Levin, B. (2002). Telicity corresponds to degree of change. Paper presented at Georgetown University.

Kiparsky, P. (2002). Event structure and the perfect. In Beaver, D., Casillas Martínez, L., Clark, B. \& Kaufmann, S. (eds.), The construction of meaning. Stanford, CA: CSLI Publications. II3-I36.

Koontz-Garboden, A. (2005). On the typology of state/change of state alternations. In Booij, G. \& van Marle, J. (eds.), Yearbook of Morphology 2005. Heidelberg: Springer. 83-II7.

Koontz-Garboden, A. (2006). The states in changes of state. To appear in the Proceedings of the 32nd Annual Meeting of the Berkeley Linguistics Society [Available for download from semanticsarchive.net at http://semanticsarchive.net/Archive/GE5 NzMxO]

Koontz-Garboden, A. (2007). States, changes of state, and the Monotonicity Hypothesis. Ph.D. dissertation, Stanford University.

Koontz-Garboden, A. \& Levin, B. (2005). The morphological typology of change of state event encoding. In Booij, G., Guevara, E., Ralli, A., Sgroi, S. \& Scalise, S. (eds.), Online Proceedings of the Fourth Mediterranean Morphology Meeting (MMM4), Catania, 2I-23 September 2003. Università degli Studi di Bologna. I85-I94. < http://morbo.lingue.unibo.it/ $\mathrm{mmm} / \mathrm{mmm} 4$-proceedings.php $>$.

Kratzer, A. (2000). Building statives. In Proceedings of the 26th Annual Meeting of the Berkeley Linguistics Society. 385-399.

Lakoff, G. (1970). Irregularity in syntax. New York: Holt, Rinehart, and Winston.

Levin, B. (200I). Externally and internally caused eventualities. Handout of Ling. 232A Class Lecture, Stanford University.

Levin, B. \& Rappaport Hovav, M. (I995). Unaccusativity: at the syntax-lexical semantics interface. Cambridge, MA: MIT Press.

Levin, B. \& Rappaport Hovav, M. (I998). Morphology and lexical semantics. In Zwicky \& Spencer (eds.), 248-27I.

Lieber, R. (2004). Morphology and lexical semantics. Cambridge: Cambridge University Press.

Lin, J. (2004). Event structure and the encoding of arguments: the syntax of the Mandarin and English verb phrase. Ph.D. dissertation, MIT.

Lüpke, F. (2005). A grammar of Jalonke argument structure (MPI Series in Psycholinguistics). Nijmegen: Max Planck Institute for Psycholinguistics.

Michaelis, L. A. (I994). The ambiguity of the English present perfect. Journal of Linguistics $\mathbf{3 0 .}$ III-I57.

Michaelis, L. A. (2004). Type shifting in construction grammar: an integrated approach to aspectual coercion. Cognitive Linguistics I5. I-67. 


\section{ANDREW KOONTZ-GARBODEN}

Mittwoch, A. (1988). Aspects of English aspect: on the interaction of perfect, progressive, and durational phrases. Linguistics and Philosophy II. 203-254.

Moens, M. \& Steedman, M. (1988). Temporal ontology and temporal reference. Computational Linguistics I4. I5-28.

Nedjalkov, V. \& Silnitsky, G. (1973). The typology of morphological and lexical causatives. In Kiefer, F. (ed.), Trends in Soviet theoretical linguistics. Dordrecht: D. Reidel Publishing. I-32.

Olsen, M. B. (1996). A semantic and pragmatic model of lexical and grammatical aspect. Ph.D. dissertation, Northwestern University. [Published 1997 by Garland.]

Otsuka, Y. (2000). Ergativity in Tongan. Ph.D. dissertation, University of Oxford. [Available online at author's website $<$ http://www2.hawaii.edu/ yotsuka/ $>$.]

Parsons, T. (1990). Events in the semantics of English: a study in subatomic semantics. Cambridge, MA: MIT Press.

Portner, P. (2003). The (temporal) semantics and (modal) pragmatics of the perfect. Linguistics and Philosophy 26. 459-5IO.

Pustejovsky, J. (1995). The generative lexicon. Cambridge, MA: MIT Press.

Pustejovsky, J. \& Bouillon, P. (I995). Aspectual coercion and logical polysemy. Journal of Semantics I2. 133-I62.

Rappaport Hovav, M. \& Levin, B. (1998). Building verb meanings. In Butt, M. \& Geuder, W. (eds.), The projection of arguments: lexical and compositional factors. Stanford, CA: CSLI Publications. 97-I34.

Rappaport Hovav, M. \& Levin, B. (2002). Change of state verbs: implications for theories of argument projection. In Proceedings of the 28th Annual Meeting of the Berkeley Linguistics Society. 269-280.

Reichenbach, H. (1947). Elements of symbolic logic. New York: The Free Press.

Sadler, L. \& Spencer, A. (1998). Morphology and argument structure. In Zwicky \& Spencer (eds.), 206-236.

Sasse, H.-J. (2002). Recent activity in the theory of aspect: accomplishments, achievements, or just non-progressive state? Linguistic Typology 6. 199-27I.

Smith, C. (1997). The parameter of aspect (2nd edn.). Dordrecht: Kluwer.

de Swart, H. (1998). Aspect shift and coercion. Natural Language \& Linguistic Theory I6. $347-385$.

Talmy, L. (1985). Lexicalization patterns. In Shopen, T. (ed.), Language typology and syntactic description (vol. 3). Cambridge: Cambridge University Press. 57-I49.

Taylor, B. (1977). Tense and continuity. Linguistics and Philosophy I. 199-220.

Tchekhoff, C. (1984). Une langue sans opposition verbo-nominale: le tongien. In Modèles linguistiques 6. I25-I32.

Van Valin, R. D., Jr. \& LaPolla, R. J. (1997). Syntax: structure, meaning, and function. Cambridge: Cambridge University Press.

Weber, D. (1989). A grammar of Huallaga (Huánuco) Quechua. Berkeley: University of California Press.

Weber, D. J., Zambrano, F. C., Villar, T. C. \& Dávila, M. B. (I998). Rimaycuna, quechua de Huánuco: diccionario del quechua del Huallaga con índices castellano e ingles (prelim. edn.). Lima, Peru: Instituto Lingüístico de Verano.

von Wright, G. H. (1963). Norm and action. New York: Humanities Press.

von Wright, G. H. (I968). An essay in Deontic logic and the general theory of action (Acta Philosophica Fennica). Amsterdam: North Holland.

Zucchi, A. (1998). Aspect shift. In Rothstein, S. (ed.), Events and grammar. Dordrecht: Kluwer. 349-370.

Zwicky, A. \& Spencer, A. (eds.) (1998). Handbook of morphology. Oxford: Blackwell.

Author's address : Linguistics and English Language, School of Languages,

Linguistics and Cultures, The University of Manchester,

Manchester MI3 9PL, U.K.

E-mail:andrewkg@manchester.ac.uk 